\title{
Introduction and control of three invasive mosquito species in the Netherlands, July-October 2010
}

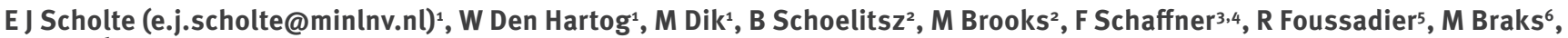
J Beeuwkes ${ }^{1}$

1. National Centre for Monitoring of Vectors (CMV), New Food and Consumer Product Safety Authority (nVWA), Dutch Ministry of Economic Affairs, Agriculture and Innovation, Wageningen, the Netherlands

2. Kenniscentrum Dierplagen (KAD), Wageningen, the Netherlands

3. Agriculture and Veterinary Information and Analysis (Avia-GIS), Zoersel, Belgium

4. Institute of Parasitology, University of Zurich, Switzerland

5. Entente Interdépartementale (EID) Rhone-Alpes, Chindrieux, France

6. Laboratory for Zoonoses and Environmental Microbiology, Centre for Infectious Disease Control (RIVM), the Netherlands, Bilthoven, the Netherlands

Scholte EJ, Den Hartog W, Dik M, Schoelitsz B, Brooks M, Schaffner F, Foussadier R, Braks M, Beeuwkes J. Introduction and control of three invasive mosquito species in the Netherlands, July-October 2010. Euro Surveill. 2010;15(45):pii=19710. Available online: http://www.eurosurveillance.org/ViewArticle.

aspx?Articleld $=19710$

In July 2010, during routine mosquito surveillance inspections at companies that import used tires, three invasive species were found at five locations in the Netherlands: the yellow fever mosquito (Aedes aegypti), the Asian tiger mosquito (Ae. albopictus), and the American rock-pool mosquito (Ae. atropalpus). This is the first time that Ae. aegypti is reported from the Netherlands. Mosquito control was initiated one week after the first invasive mosquito was found, using adulticides and larvicides. The available data suggest that the implemented control measures have been effective for this season.

\section{Introduction}

Following the discovery of Aedes albopictus in the Netherlands in 2005 related to companies that import Lucky bamboo [1], continuous surveillance at these companies was started in 2006. Gradually, other national surveillance activities for this mosquito species were initiated, including passive surveillance (since 2007), active surveillance at parking lots along main highways entering the country from the south and east (since 2008), and at companies that import used tires (since 2009). In 2009, during routine surveillance activities, the exotic mosquito species Ae. atropalpus, a North American species that had been encountered several times in Europe [2], but had never established here, was found for the first time in the Netherlands [3].

These surveillance activities are meant to identify as early as possible the presence of exotic mosquito species with the aim to prevent the establishment of invasive exotic mosquito species, especially those that are known to be vectors of pathogens of public health importance such as dengue- and chikungunya virus. Here we report the finding and the successive con- trol of three invasive mosquito species, Ae. aegypti, Ae. albopictus and Ae. atropalpus in the Netherlands.

\section{Methods}

A total of 34 companies that import used tires into the Netherlands were included in the invasive mosquito survey. Routine inspections were carried out from April to the last week of October [2]. A qualitative risk assessment on the introduction of invasive mosquito species was performed to determine the frequency of inspection of a company. Parameters in the risk assessment were (i) the type of tires that are imported, (ii) the countries from which tires are imported, and (iii) whether the tire storage is in- or outdoors. Collected larvae and adult mosquitoes were diagnosed either morphologically by using the diagnostic keys from Schaffner et al. [4], or molecularly by PCR sequencing the mitochondrial cytochrome oxidase subunit 1 ( $\mathrm{CO}_{1}$ ) gene [5]. A week after the first finding, infested locations were treated by spraying Bacillus thuringiensis israelensis (B.t.i.) serotype H14 or Bacillus sphaericus (B.s.) against larvae and/ or deltamethrin (aqua K-Othrine, Bayer Environmental Sciences) against adult mosquitoes. Larval control of the surrounding area (predefined perimeter of 500 $\mathrm{m}$ ) consisted of removal of potential larval habitats for container-breeding Aedes spp. when possible, or treatment with either B.t.i. space spray (VectoBac WG, Valent BioSciences), or with B.t.i./Bacillus sphaericus (B.s.) granules (Vectomax, Valent BioSciences). It was decided to perform larvicidal treatment once every two to three weeks, until the first week of November.

Following the discovery of an exotic species at a location, surveillance was intensified to assess the potential spread of the invasive species and the effectiveness of the control activities by placing traps for adult mosquitoes (BG-sentinel, Biogents) and oviposi- 
tion traps [6] in the $500 \mathrm{~m}$ perimeter surrounding the company site.

\section{Results}

Three exotic mosquito species (Ae. aegypti, Ae. albopictus, and Ae. atropalpus) were found in five locations in the Netherlands. The first two mosquito larvae, Ae. atropalpus, were found on 21 July 2010, during a routine inspection at Location 1 (Heijningen) (Figure, Table 1).

On the next day, during an intensified inspection, one adult $A e$. albopictus and one adult Ae. aegypti were collected, in addition to the two initial Ae. atropalpus larvae. The infestation level for Ae. atropalpus (in terms of percentage of infested tires and total number of larvae) at this company was relatively high, but less so for Ae. albopictus and Ae. aegypti, of which no larvae and/ or pupae were found. Results of intensified inspection suggest that Ae. atropalpus and Ae. albopictus (but not $A e$. aegypti) had spread to the surrounding areas of Location 1. On 3 September 2010, the last exotic species was collected from Location 1 and its surroundings (Table 2).

At Location 2 (Oosterhout), several male Ae. aegypti specimens were collected starting with 26 July. The last invasive species were found at this location on 6 August, when two adult $A e$. atropalpus were collected. Despite intensive surveillance, no immature forms of invasive species were found at the company's premises or in the surrounding areas.

\section{FIGURE}

Locations of tire companies that were positive $(n=5)$ and negative $(n=29)$ for at least one of the invasive mosquito species, the Netherlands, 2010

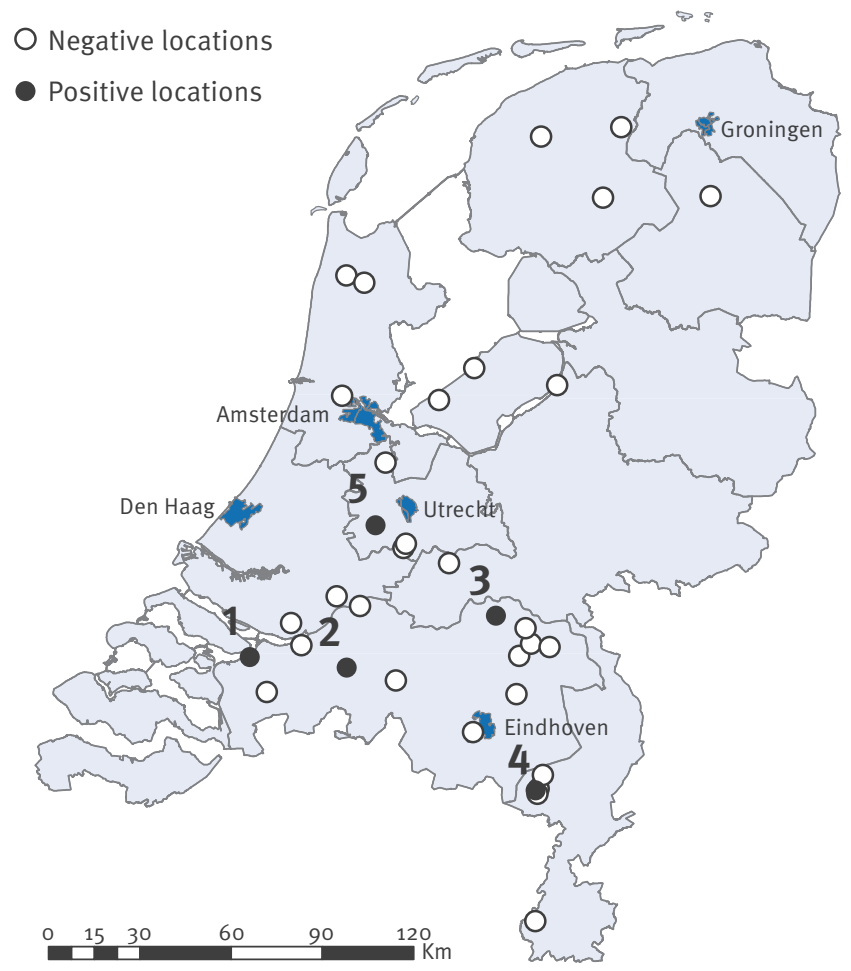

On 26 July, three adult specimens (but no larvae) of Ae. atropalpus were collected from Location 3 (Oss). In addition, another three adult Ae. atropalpus were found on 5 August at this location. In the surrounding area, one Ae. albopictus was collected in a BG-sentinel trap placed approximately $50 \mathrm{~m}$ from the tire platform on 9 August, but no larvae of exotic species were found in the surrounding area. The last specimen (larva) was found at this location on 23 August.

On 24 August, the first larvae (six specimens) of $A e$. atropalpus were collected from Location 4 (Weert). On 13 September, high numbers of this species (larvae and adults) were found at this location and several larvae were found in the surrounding area, including at the premises of a neighbouring tire-importing company. The two companies are considered as one location (Location 4). In addition, one Ae. albopictus specimen was collected from the tire platform on 13 September and one Ae. albopictus specimen was found in a BG sentinel trap at approximately $25 \mathrm{~m}$ from the infested companies, one week later. The last specimen was found on 27 September.

On 28 September, two Ae. albopictus larvae were collected from Location 5 (Montfoort). The third (and last) specimen was collected in an adult trap on the tire platform on 5 October. No specimens were found in the surrounding area.

All infested companies described here belong to the 'high risk'-category for importing exotic mosquito species, based on the type, origin and storage of the tires that are imported, and are therefore inspected every two weeks. No invasive mosquito species were found at any of the other companies that were included in the survey.

\section{Discussion and conclusion}

The discovery of Ae. aegypti in the Netherlands was unexpected, mostly because, unlike $A e$. albopictus [3], Ae. aegypti is not directly associated with the international trade in used tires [7]. Even without control measures, the tropical Ae. aegypti will probably not survive the winter in temperate areas such as the Netherlands and consequently does not pose a direct health risk for the country. This is in contrast with the public health risks related to re-introduction of $A e$. aegypti into southern Europe $[8,9]$.

In addition, this report describes the discovery of an Ae. albopictus for the first time in the outdoor environment in the Netherlands. Although the species is still regularly found in glasshouses as hitchhikers in importation of Lucky bamboo [10], preventive and curative indoor control measures in these glasshouses appear to be effective to prevent indoor or outdoor establishment, since a location never stays positive for $A e$. albopictus longer than 1,5 month (Scholte, unpublished data). 
Back-tracing data of the company at Location 1 suggests introduction of Ae. albopictus and Ae. aegypti by a shipment of used airplane tires at the end of May 2010, originating from southern Florida, an area inhabited by both species. On 24 July, part of the same shipment was transported to Location 2 (belonging to the same company), and on 4 August to Location 3. Back-tracing information of the companies at Location 4 showed recent tire import from Italy. Ae. albopictus from Italy [11] and the United States [12] are considered to display diapause and potentially to survive temperate climates $[13,14]$. Ae. atropalpus had already been found at two sites in the Netherlands in 2009 [2] which indicates that the first introduction of Ae. atropalpus was in or before 2009, although more recent introductions are not excluded either. This species had a relatively large population at Locations 1 and 4, and colonised larval habitats in the surrounding areas, other than tires.

The fact that relatively few adults and no other lifestages of Ae. aegypti and Ae. atropalpus were found at Location 2, indicates a low level of infestation.

The available data for this season (Table 2) suggest that the implemented control measures have been effective, although it is too early at this moment in time to assess if eradication has been achieved. Per location, it took between one and three treatments and a maximum time span of seven weeks between the first treatment and the day when the last exotic species was found. It will be crucial in the years to come to monitor the locations (including the surrounding areas) that had been infested with one or more of the exotic species in 2009 and 2010, in order to restart mosquito control as early as possible.

Having witnessed these introductions of exotic invasive mosquito species that pose a potential threat to public health in Europe, international collaboration and action of medical entomologists, public health experts, policy makers, and the tire-business industry is critical to address this.

\section{Acknowledgements}

Roel Coutinho (RIVM), Marleen Kraaij-Dirkzwager (Ministry of VWS), Corien Swaan (RIVM), André Jacobi (RIVM), Peter de Vries (VROM), Martin van den Homberg (nVWA), Ad Dilven (GGD West Brabant), Roel Vincken (nVWA), Nicole Bouwer (nVWA), Arie Verhoef (VACO), Robert Luttik (RIVM), Heiko Kotter (Sumitomo).

TABLE 1

Summary of the results of the invasive mosquito survey at used tire companies by location, the Netherlands, July-October 2010

\begin{tabular}{|c|c|c|c|c|c|c|c|c|}
\hline \multirow{2}{*}{ Location } & \multicolumn{4}{|c|}{ Adults collected } & \multicolumn{4}{|c|}{ Larvae collected } \\
\hline & Ae. aegypti & Ae. albopictus & Ae. atropalpus & Total & Ae. aegypti & Ae. albopictus & Ae. atropalpus & Total \\
\hline 1 & 5 & 11 & 68 & 84 & 0 & 0 & 80 & 80 \\
\hline 2 & 8 & 0 & 2 & 10 & 0 & 0 & 0 & 0 \\
\hline 3 & 0 & 1 & 6 & 7 & 0 & 0 & 1 & 1 \\
\hline 4 & 0 & 2 & 45 & 47 & 0 & 6 & 122 & 128 \\
\hline 5 & 0 & 1 & 0 & 1 & 0 & 2 & 0 & 2 \\
\hline Total & 13 & 15 & 121 & 149 & 0 & 8 & 203 & 211 \\
\hline
\end{tabular}

\section{TABLE 2}

Inspections, mosquito control, and findings of at least one of the three exotic mosquito species for each location per week, the Netherlands, July-October 2010

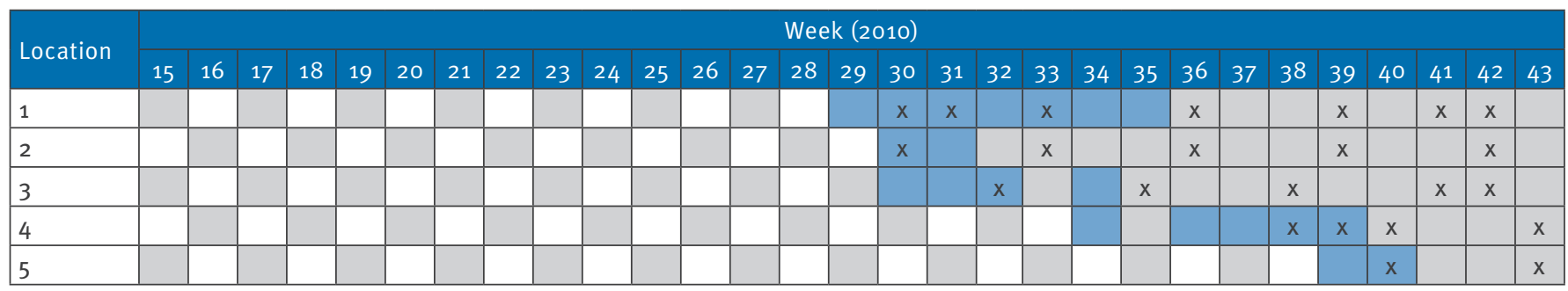

$\square$ No inspection

$\square$ No exotic species found (negative)

$\square$ Larvae and/or adults found of one of the three exotic mosquito species

$\mathrm{X}$ Control measures 


\section{References}

1. Scholte EJ, Jacobs F, Linton YM, Dijkstra E, Fransen J, Takken W. 2007. First record of Aedes (Stegomyia) albopictus in the Netherlands. Euro Mosq Bull. 2007;22:5-9.

2. Schaffner F, Van Bortel W. Current status of invasive mosquitoes in Europe. European Centre for Disease Prevention and Control; 31 Jan 2010. Available from: http://www.ecdc. europa.eu/en/activities/sciadvice/Lists/ECDC\%20Reviews/ ECDC DispForm.aspx?List $=512 \mathrm{ff} 74 \mathrm{f}-77 \mathrm{~d} 4-4 \mathrm{ad} 8-\mathrm{b} 6 \mathrm{~d} 6$ bfof 23083 f3o\&ID =758\&RootFolder=/en/activities/sciadvice/ Lists/ECDC\%20Reviews\&MasterPage=1

3. Scholte EJ, Den Hartog W, Braks M, Reusken C, Dik M, Hessels A. First report of a North American invasive mosquito species Ochlerotatus atropalpus (Coquillett) in the Netherlands, 2009. Euro Surveill. 2009;14(45):pii=19400. Available from: http:// www.eurosurveillance.org/ViewArticle.aspx?Articleld=19400

4. Schaffner F, Angel G, Geoffrey B, Hervy J-P, Rhaiem A, Brunhes J. The mosquitoes of Europe. CD-ROM. Montpellier: Institut de Recherche pour le Développement/Entente interdépartementale pour la démoustication du littoral (EID) Méditerrannée ; 2001.

5. Simon C, Frati F, Beckenbach A, Crespi B, Liu H, Flook P. Evolution, weighting, and phylogenetic utility of mitochondrial gene sequences and a compilation of conserved polymerase chain reaction primers. Ann Entomol Soc America. 1994;87(6):651-701.

6. Fay RW, Eliason DA. A preferred oviposition site as a surveillance method for Aedes aegypti. Mosq News. 1966;26:531-5.

7. Schaffner F. Mosquitoes in used tyres in Europe: species list and larval key. Eur Mosq Bull. 2003;16:7-12.

8. Theiler M, Casals J, Moutousses C. Etiology of the 192728 epidemic of dengue in Greece. Proc Soc Exp Biol Med. 1960;103:244-6.

9. Reiter P. Yellow fever and dengue: a threat to Europe?. Euro Surveill. 2010;15(10):pii=19509. Available from: http://www. eurosurveillance.org/ViewArticle.aspx?Articleld=19509

10. Scholte EJ, Dijkstra E, Blok H, De Vries A, Takken W, Hofhuis A, et al. Accidental importation of the mosquito Aedes albopictus into the Netherlands: a survey of mosquito distribution and the presence of dengue virus. Med Vet Entomol. 2008;22(4):352-8.

11. Romi R, Severini F, Toma L. Cold acclimation and overwintering of female Aedes albopictus in Roma. J Am Mosq Control Assoc. 2006;22(1):149-51.

12. Lounibos LP, Escher RL, Lourenço-de-Oliveira R. Asymmetric evolution of photoperiodic diapause in temperate and tropica invasive populations of Aedes albopictus (Diptera: Culicidae). Ann Entomol Soc Am. 96(4):512-18.

13. European Centre for Disease Prevention and Control (ECDC). Development of Aedes albopictus risk maps. Technical report. Stockholm:ECDC. 2009. Available from: http://ecdc.europa. eu/en/publications/Publications/0905_TER_Development_of_ Aedes_Albopictus_Risk_Maps.pdf

14. Takumi K, Scholte EJ, Braks M, Reusken C, Avenell D, Medlock JM. Introduction, scenarios for establishment and seasonal activity of Aedes albopictus in the Netherlands. Vector Borne Zoonotic Dis. 2009;9(2):191-6. 